\title{
Virtual Family: Forms and Functions ${ }^{1}$
}

\author{
Anna Vladimirovna Artamonova \\ Volga State University of Technology; Email: sci.publ@gmail.com
}

\section{Doi:10.5901/mjss.2015.v6n6s4p572}

\begin{abstract}
In this paper we study the possibility of identifying a new type of family relations - the virtual family. A definition of the virtual family is put forward, there are described its functions and causes which make each type of the virtual family come into existence. The development of social and technological (virtual) environment changes man's needs and thus transforms the meaning and essence of the family ascribing to the family new functions. We also suggest taking into account "the image of the family" created in science, public opinion and mass media as a type of virtual family relationship.
\end{abstract}

Keywords: Virtual family, family types, virtual reality, functions of the family, family relations, social philosophy.

\section{Introduction}

We live in the age of rapid technological development when such notions as «IT-technology", "cyberspace", "virtual reality", "virtual" have become quite common. The notion of "virtuality" denotes an object or a state that does not exist in reality but may come into existence under certain conditions (Ruzavin, 2010). These conditions were created by computer and technological revolution for functioning of virtual reality. Virtual reality is a new way of existence of many phenomena and objects. The image of the real world is virtual by nature but a virtual image can not exist on its own, independently of reality that makes its existence possible. Therefore, in virtual reality images do not differ from "real" ones, those of the real world outside. Plunging into virtual reality created by technology, man can lose a sense of objective reality and immerse himself in experiencing totally new sensations. That is, together with technological (or computer) virtual reality, man creates his own reality - psychological virtual reality (the Virtual). The Virtual is always perceived as going beyond the borders of usual life (Virtual approach to the problem of man, 2001).

\section{Research Methods}

The idea about the family crisis, the destruction of its functions and values has become popular recently. A variety of forms of existence of the modern family (constant reality) creates a new type of family relations - the virtual family. Researching into the phenomenon of the virtual family it is necessary to find out what event or phenomenon of constant reality creates this or that form of the virtual family and what its final objective is (its function).

To single out the virtual family types and to research into its forms and functions the comparative analysis, the structural and functional approach, social and philosophical analysis were used.

\section{Findings and Discussion}

According to Russian philosopher V.M.Rosin, there are seven basic family functions that distinguish the real family from the virtual image of the family (in the virtual family these functions can be realized too, but only partially): 1) stabilization of the social status, position in society, life prospects; 2) organization of intimate life, providing physical and spiritual health, mental balance; 3) communication with close people, sharing the same interests; 4) ensuring reproduction (which makes man "step with his one foot in eternity, becoming immortal"); 5) reducing the devastating impact of external forces on man by sharing parental duties, solving domestic problems and overcoming other difficulties; 6) experiencing gratitude to the spouse, responsibility for future children, being part of the kindred, etc; 7) providing support, help and care for people in declining years (Rozin, 2006). The virtual family can be treated as a special kind of human relations that imitates family relations, as, in fact, these relations, being virtual, do not really exist.

\footnotetext{
1 The publication is prepared within the framework of a research project accepted and supported by the RFH\#13-33-01294.
} 
We suggest distinguishing three basic types of the virtual family, each of them has its own Virtual. As psychologists think, the Virtual is a psychic reality created by man to solve certain problems. They can be positive (when the gradual, i.e. the desired image, is formed) or negative (when the ingratual, i.e. the scaring image, is formed). The Virtual as different from other psychic derivatives, like e.g. imagination, is characterized by the fact that man perceives it and "funnels" it through himself not as a product of his own mind but as the objective reality (Ruzavin, 2010). We can consider the following formations as the virtual family:

1) "the image of the family" in science and public opinion - it is the Virtual created by a researcher or a society to name a certain state of the family or to prove his conception,

2) "the psychological / social" virtual family - it is the Virtual in which a union which is not officially registered or not accepted by a society, or a family which is falling apart, are considered a family by those people who are involved in these relations,

3) "the technological / computer" virtual family - it is the Virtual which exists thanks to virtual reality (the Internet), social networks, communication software and computer games.

The boundaries between these family types are rather conventional as well as virtual reality itself. We try to identify the functions of each type of the virtual family and give examples from social practice. The first type of the virtual family, "the image of the family" in science and public opinion ("the virtual of the researcher"), is created by researchers or social groups to prove that they understand the idea of the family correctly (this is what I am trying to do in this article). The main function of this virtual family type (which is the product exclusively of scientific concepts or social ideas) is illustration because the objective of researchers / social groups is to prove their ideas. Creating "the virtual of the researcher" is not an abstract process, it is based on a prototype or a source from objective reality (perhaps, these are only singular events).

However, becoming a part of scientific discussions and mass media "the virtual of the researcher" ("the image of the family") can grow into reality and change social practices. Many people use scientific research (even if it is only a hypothesis) or social beliefs as guidelines for actions but not as evaluation criteria or possible strategies of family life organization. Therefore, a researcher / a social group and mass media, creating "the image of the family" (the Virtual), have great social and moral responsibility for consequences of its impact on constant reality. Erich Fromm, as far back as in the middle of the 20th century, remarked that "eventually, only to the extent to which he grasps reality, can he make this world his; if he lives in illusions, he never changes the conditions which necessitate these illusions" (Fromm, 2002).

"Civil marriages", "non-traditional families" (guest marriage, menage a trois, samesex unions, swinging), "technological / computer" virtual families like "Skype-families", "game families", "families by correspondence" (in social networks or special websites, forums, chat rooms, e-mail) can serve examples of the "psychological / social" virtual family. It should be noted that this division into "psychological / social" and "technological / computer" forms of the virtual family is rather conventional, it reflects its main peculiarity, i.e. conditions and causes of its origin. Any virtual family form can exist only if a person is psychologically ready to form and maintain it. The aim of any virtual family form is satisfying only individual needs of a person, to help him bolster and preserve his self-esteem.

Erich Fromm considered that "our ego is the most important object of our property feeling, for it comprises many things: our body, our name, our social status, our possessions (including our knowledge), the image we have of ourselves and the image we want others to have of us. Our ego is a mixture of real qualities, such as knowledge and skills, and of certain fictitious qualities that we build around a core of reality. But the essential point is not so much what the ego's content is, but that the ego is felt as a thing we each possess, and that this «thing» is the basis of our sense of identity" (Fromm, 2008). Moving the center of one's life to virtual reality is like "robbing" oneself, consuming oneself as if you were a thing.

As stated above, "the psychological / social" virtual families exist in two forms: "civil marriages" and "non-traditional families." The term "civil marriage" means cohabitation, i.e. a union of a man and a woman which is not officially registered and is treated by society as temporary relations ("relations put on trial"), without any obligations and social status change. In this case family relations are virtual as social functions of the family are not fulfilled:

- there is no stabilization of social status. The paradox of the Russian census of 2010 is remarkable as the number of married women was much higher than the number of married men. The explanation is the following: women who are involved in civil marriages consider themselves married, while men - not;

- from the very start relations are viewed as temporary, people don't think of living together when becoming old, of having common property and, very often, offspring.

According to Z.Bauman, the main peculiarities of modern life are lack of reliability, security and certainty: "precarious economic and social conditions train man and woman (or make them learn the hard way) to perceive the world as a container full of disposable objects, objects for one-off use of the whole world - including other human beings" 
(Fromm, 2006). We think that V.G.Fedotova is right stating that "planning that human relations are going to be temporal is completely different from no planning their duration at all or from any duration even of unhappy relations. This style of having something just temporary makes people cut off and separate and doesn't help the family to be everlasting" (Fedotova, 2005). Living in such unions can be compared to a permanent process of examination taking, when the award is an officially registered marriage, which will though also bear the stamp of inconsistency. In fact, such relations can be called family relations only if to treat them as virtual. However, they perform their functions, i.e. freedom in selecting a partner and time for family life (on their own, without any intervention of society and government), minimizing damages in cases of failure, sense of control and management of their lives.

The next type is Swinging ("partner sharing family"), it is a "non-traditional family" in which the principle of relationship is free sharing of partners (wives, husbands) for sexual activities; the family usually has two partners but sometimes there are commune families. This form of the family, in our view, is also virtual. It is difficult to establish paternity and from the social point of view it creates many moral and legal problems. Matrimonial relations are distorted, parent-children and brother-sister relations are mixed up, mental health and balance are problematic as well as stabilization of the social status. One of the main functions of this form of the virtual family is to add variety into people's conventional sex lives, to let them have the so-called forbidden fruit in psychological relations and experiences. This family exists only thanks to creating virtual reality common to all its members, which helps to remove psychological and social contradictions and becomes ontologically independent of constant reality.

"The Skype family" can be treated as both "technological" and "psychological" virtual families; it is a type of interpersonal communication which is carried out by means of the communication software Skype which let people communicate by writing messages, making telephone calls and using video communication thus creating the effect of real presence and face-to-face communication. It is quite a trustworthy way of communication, you can see in real time what another person is doing, where he is at the moment, with whom, what his state and mood are. Of all the other technological forms of the virtual family it is least of all anonymous. As our life is very dynamic nowadays, this form is sometimes the only possible way of communication with our close people. It is quite a common situation now when one spouse is in some city / town (region, country, part of the world), and the other one is in another. But is it a real family? It is sure to perform the function of communication, it helps to experience and to share feelings and emotions, let a person have his status of a married man (only via communication), but all challenges in real life each spouse has to face on his own relying only on his abilities and possibilities.

"The Game family" is not a technological form pure as well, as the psychological element is involved here too. But as different from the "Skype family" communication in the "Game family" is mostly anonymous: who knows who can hide himself under "nicknames" (nicknames used in this or that network) and "user icons" (pictures, game characters) which are only virtual (invented, designed) persons? That is why communication in this case is more relaxed, open, we can observe the so-called "random passenger syndrome". There is a possibility to freely express and select your own sexual identity, not limited by gender, moral or social rules. As Anthony Giddens said, "as anatomy stops being destiny, sexual identity more and more becomes a life-style issue. Sexual identity could become formed through diverse configurations of traits connecting appearance, demeanour and behavior" (Fedotova, 2005)There are special network games the subject of which is family (for example, "Sims"), there are special forums and chat rooms, dating websites, but this form can come into existence during any network game or at any thematic forum. The peculiarity of this family form is that the participants ("spouses") from the very start understand the artificiality of this form of family relations, and treat it as a game, an entertainment. But not all people. And not always. Its main functions are psychological compensation (people seem to be in relations but in real time they do not have any responsibilities), communication and entertainment.

"The Family by correspondence" is similar to "the Game family" as the both share the same place of existence (forums, chat rooms, social networks) and sometimes communication forms (electronic messages); but it is different in its essence. The majority of people involved in this form of relationship suggest that the partner has serious intentions (no game component), treat this online communication as an intermediate stage leading to real relationship (offline), and often it happens so. In this case communication is also anonymous, many people hide their personalities inventing data and using other people's photos, they create a desired image with no effort and expense (special services in social networks have this function providing music, photo, motivator and famous quote contents for the user to fill his profile and create his "face"). The main functions of this form of the virtual family are communication, psychological compensation and helping to overcome loneliness. The key factor is the freedom of choice - time of communication, place, ways, subjects; you can stop it at any time by your wish, distort the objective reality (cheating) and there is almost no responsibility for that in real time, a person feels his power and impunity. As Manuel Castells says, "the Internet seems also to play a positive role in maintaining strong ties at a distance... Not only does e-mail provide an easy tool to "just be there" at a distance, but it makes it easier to mark a presence without engaging in a deeper interaction for which the 
emotional energy is not available every day" (Castells, 2001). In face-to-face communication on daily basis we do not have so many possibilities like this and thus our life turns into routine. But in the "technological" virtual family you are always right, powerful, you have a chance to prepare for communication and think over your position, you can control the situation. Russian researchers who study the information society (I.Y.Alekseev and others) suggest a change in the relationship between man and his virtual environment which is to occur in the near future due to its rapid evolution: "the formation of a new type of a hybrid reality presupposes anthropomorphizing virtual reality, imbuing it with human reasoning by its acquiring elements of digital identity, memory, computing, perceptual and communicative features (wireless sensors connected to the Internet). The connection between environments is possible thanks to overlaying additional "layers" of virtual reality, greater possibilities of operating with objects in real life using image identification, reading digital labels, pairing sensors and actuators of the real world with the virtual space of the World Wide Web. The result is "the Internet of things" (Alekseeva, I.Y., Arshinov, V.I., Tchekletsov, V.V , 2013). This technological breakthrough can radically change the correlation between real life and virtual life, and lead to final blurring the boundaries of the notion of "the family".

The youth are the most active social group, they are most of all involved in virtual reality and are subject to the information influence (the Virtuals' intervention). To find out what young people really think about the family a special survey was conducted. The respondents were 457 students from the Mari El Republic, aged 17 - 25 (35\% of them were boys, $65 \%$ - girls). As the results of the survey show the family has a top position in the hierarchy of values of young people (98\%). However, their ideas about the essence and structure of the family are vague: the majority ( $81 \%$ of girls and $74 \%$ of boys) define the family as an officially registered union of a man and a woman with children born in it; $5 \%$ of girls and $10 \%$ of boys think that a single parent with a child is also a family (in the questionnaire many of them wrote the words "an incomplete family"); $8 \%$ of girls and $6 \%$ of boys think that an officially registered union of a man and a woman even without children is also a family; $5 \%$ of girls and $7 \%$ of boys consider that a union of a man and a woman, with children but which is not officially registered can be called a family; and $1 \%$ of girls and $3 \%$ of boys think that a homosexual union without children can be treated as a family.

It's noteworthy that nearly no one (except 1 or 2 persons) considers as a family an officially unregistered union of a man and a woman without children, and the union of homosexuals with children. The unregistered union between a man and a woman is defined by the students as civil marriage, but the marriage and the family are different things in their opinions. To our mind, this can be explained by lack (or rejection) of role models (established Virtuals) of such forms of relationship in the popular youth culture in the Russian province. Despite these blurring notions of the family as a whole, the students are more inclined to the traditionalist interpretation of the family as an institution of marriage and childbearing. The majority of the students (95\%) use technical devices to keep in touch with their relatives and beloved, but they do not consider that these relations can be serious if they were completely moved to virtual reality. Many students expressed their concern about the increasing tendency of having love and family relations in virtual reality which, unnoticeably for our eye, replaces real communication by the mediated (the Internet, telephone) reality; when feelings and emotions are expressed by some formal reactions (a parody of emoticons and Internet memes); when there is no feeling of being a part of a crowd and community (everyone "lives" inside his gadget with the phantom idea of being together).

\section{Concluding Remarks}

Thus, all the forms of the virtual family which we single out can be considered virtual from the point of view of social and functional approach and stereotypes and traditions of family relations accepted by society. When considering the virtual family (and its forms mentioned above) as a part of virtual reality, we find that it satisfies the following specific features: 1) being begotten (new conditions which do not fit into usual accepted norms, create various forms of the virtual family); 2) being actual (the virtual family exists actually, "here and now" till exists the reality that generates it); 3) being independent (the virtual family has its own rules of existence, functions and forms. A person who finds himself in this virtual reality, feels it and uses it; and a person who finds himself in constant reality is to follow objective social laws); 4) being interactive (the virtual family can interact with all other family types - as well as reality that engenders it - being ontologically independent of them) (Virtual approach to the problem of man, 2001). The family is very sensitive to any changes not only of social conditions and cultural preferences, but also of the type of personality and psychological needs of man. It develops ways to adapt to them, in particular, by becoming virtual but remaining an active participant influencing man's life. 


\section{Acknowledgement}

To the Russian Foundation for Humanities for providing me with an opportunity to write and publish this article as a part of accepted research project \#13-33-01294. (as agreed with the RFH the following definition is used - The publication is prepared within the framework of a research project accepted and supported by the RFH \#13-33-01294.)

\section{References}

Alekseeva, I.Y., Arshinov, V.I., Tchekletsov, V.V. «Techno-people» vs "post-people": NBICS-revolution and future of man // Questions of Philosophy. 2013. \# 3. - pp:12-22.

Bauman, Z., 2006. Liquid Modernity. Cambridge: Polity Press, pp: 162.

Castells, M., 2001. The Internet Galaxy: Reflections on the Internet, Business, and Society. New York: Oxford University Press, Inc., pp: 130.

Fedotova, V.G. Factors influencing changes in values in the West and in Russia // Questions of Philosophy. 2005. \# 11. - pp: 12.

Fromm, E., 2002. The Sane Society. London: Routledge Classics, pp: 67.

Fromm, E., 2008. To have or to be?. New York: Continuum, pp: 59.

Giddens, A., 1992. The Transformation of Intimacy. Sexuality, Love and Erotism in Modern Societies. Stanford: Stanford University Press, pp: 199.

Rozin, V.M. Love in the mirror of philosophy, science and literature. - M.: Moscow social studies and psychology institute, 2006. - P. 392.

Ruzavin, G.I. Virtuality // New Philosophy Encyclopedia. Volume 1. A-D. - M.: Mysl, 2010. - P. 404.

Virtual approach to the problem of man // Many-sided image of man: Complex interdisciplinary study of man. - M.: Nauka, 2001. 